\title{
\begin{tabular}{l|l} 
Mibraries & DSpace@MIT
\end{tabular}
}

\author{
MIT Open Access Articles
}

\section{Integrating optics and micro-fluidic channels using femtosecond laser irradiation}

The MIT Faculty has made this article openly available. Please share how this access benefits you. Your story matters.

Citation: Anderson, T. et al. "Integrating optics and micro-fluidic channels using femtosecond laser irradiation." Commercial and Biomedical Applications of Ultrafast Lasers IX. Ed. Joseph Neev et al. San Jose, CA, USA: SPIE, 2009. 72030I-9. (C) 2009 SPIE--The International Society for Optical Engineering

As Published: http://dx.doi.org/10.1117/12.815306

Publisher: The International Society for Optical Engineering

Persistent URL: http://hdl.handle.net/1721.1/52723

Version: Final published version: final published article, as it appeared in a journal, conference proceedings, or other formally published context

Terms of Use: Article is made available in accordance with the publisher's policy and may be subject to US copyright law. Please refer to the publisher's site for terms of use. 


\title{
Integrating Optics and Micro-fluidic Channels Using Femtosecond Laser Irradiation
}

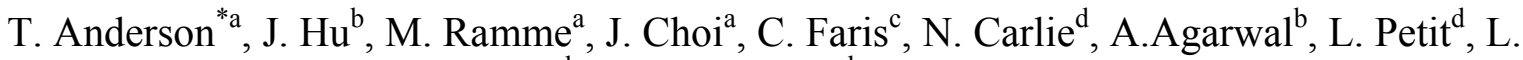 \\ Kimerling $^{\mathrm{b}}$, K. Richardson ${ }^{\mathrm{d}}$, M. Richardson ${ }^{\mathrm{a}}$ \\ ${ }^{a}$ Townes Laser Institute, College of Optics and Photonics, University of Central Florida \\ 4000, Central Florida Blvd, Orlando FL USA 32816-2700 \\ ${ }^{b}$ Microphotonics Center, MIT, Cambridge, MA 02139, USA \\ ${ }^{c}$ Coe College, 1220 First Avenue NE, Cedar Rapids IA USA 52402 \\ ${ }^{\mathrm{d} S c h o o l ~ o f ~ M a t e r i a l s ~ S c i e n c e ~ a n d ~ E n g i n e e r i n g, ~ C l e m s o n ~ U n i v e r s i t y, ~} 91$ Technology Dr., Anderson, \\ SC 29625
}

\begin{abstract}
The ability to integrate micro-channels for fluid transport with optical elements is attractive for the development of compact and portable chip-based sensors. Femtosecond Laser Direct Writing (FLDW) in transparent materials is a powerful tool for the fabrication of such integrated devices. We demonstrate the use of FLDW to fabricate coupled micro-fluidic channels and optical waveguides towards an integrated sensing device for molecular detection. Waveguides were directly written into the host material and channels were formed by modifying the molecular structure through FLDW followed by wet chemical etching. Multiple host materials including chalcogenide glasses for IR detection are discussed.
\end{abstract}

Keywords: Femtosecond Direct Write Laser Processing, Chalcogenide glass, Micro-fluidics, sensors, waveguides

\section{INTRODUCTION}

The advancement of highly functional and portable Lab-on-a-chip systems for detection and monitoring of fluids has led to a rapid increase in the development of devices incorporating both microfluidic channels and optical elements [1]. Much of the research to date has focused on fabricating such devices in PDMS or oxide glass as the substrate material due to ease of processing and low material cost [2-4]. However, the use of such materials limits the functionality of the fabricated devices in the optical domain to near-IR wavelengths. Chalcogenide glasses (ChGs) offer high IR transparency, structural flexibility, and the ability to "tune" physical and optical properties through chemical composition and are thus ideal material candidates for integrated devices capable of sensing chemicals and biological toxins which have their spectral fingerprints in the mid- and far-infrared range [5-6]. In this paper, we describe the fabrication of optical elements and micro-channels on an integrated chip-based platform in chalcogenide glass through both lithographic processing and femtosecond laser direct writing. We demonstrate the fabrication of high-Q optical resonators fabricated in $\mathrm{Ge}_{17} \mathrm{Sb}_{12} \mathrm{~S}_{71}$ chalcogenide glass using a CMOS-compatible lift-off technique coupled to PDMS microchannels for the detection of isopropanol (IPA) of varying concentrations. Finally, we explain that femtosecond laser direct writing can be used to fabricate optical waveguides and to form a surface micro-channel when combined with wet chemical etching.

\section{LITHOGRAPHIC PROCESSING}

In the effort towards a miniaturized, low cost chem-bio sensor that is robustly integrated on a chip, two types of optical resonant sensing mechanisms have been theoretically evaluated and experimentally demonstrated: refractive index sensing of biological molecular species and absorption sensing of chemicals in a gaseous or aqueous environment. The

Commercial and Biomedical Applications of Ultrafast Lasers IX, edited by Joseph Neev,

Stefan Nolte, Alexander Heisterkamp, Rick P. Trebino, Proc. of SPIE Vol. 7203, 72030I

(C) 2009 SPIE · CCC code: 0277-786X/09/\$18 $\cdot$ doi: 10.1117/12.815306

Proc. of SPIE Vol. 7203 72030I-1 
former mechanism requires the detection of molecular binding-induced refractive index change near the sensor surface. The optical resonant frequency shift of a high-Q resonator can be resolved as a result of the index change. In this case, the specificity/selectivity of the sensor relies on functional surface coatings that bind only to a specific type of target molecules, such as in antibody-antigen pairs and complimentary DNA strands. Examples of such sensors include surface plasmonic resonance (SPR) sensors [7], photonic crystal sensors [8] and fiber-optic sensors [9]. For absorption sensing, the optical absorption of chemical molecules near the sensor surface leads to a detectable resonant peak extinction ratio change accompanied by a cavity Q-factor decrease. Therefore, it is possible to perform absorption spectroscopy at resonant wavelengths of a resonator that supports multiple longitudinal modes simply by measuring its transmission spectra. Similar to Fourier transform infrared spectroscopy (FTIR), the characteristic absorption fingerprint can be used to differentiate between different molecules.

In both approaches, we used a device platform comprising of high-Q chalcogenide glass resonators integrated with microfluidic channels. The advantages of such optofluidic integration are three fold: 1) compact, high-density optofluidic integration is essential for sensor device miniaturization; 2) it allows the direct interaction of analyte molecules with optical fields inside the optical resonators, in a highly controllable fashion; and 3) the high flow velocity in the channels leads to hydrodynamic thinning of boundary layers, which enhances mass transport and reduces the sensor response time.

Details of the optical resonator fabrication in $\mathrm{Ge}_{17} \mathrm{Sb}_{12} \mathrm{~S}_{71}$ chalcogenide glass bulk is described elsewhere [10-12]. PDMS (Sylgard 184 Silicone Elastomer, Dow Corning Inc.) microfluidic channels with a width of $100 \mu \mathrm{m}$ and a height of 30 $\mu \mathrm{m}$ were fabricated via replica molding. After oxygen plasma treatment, the channels were irreversibly bonded onto the chips on which the microdisks were patterned. Liquid inlet and outlet access holes were punched prior to bonding, and PTFE (polytetrafluoroethene) tubing was attached into the access holes to complete the hybrid microfluidic chip fabrication. Fig. 1 shows a top view of the $\mathrm{Ge}_{17} \mathrm{Sb}_{12} \mathrm{~S}_{71}$ optical resonators within a microfluidic channel defined by an overlaid PDMS structure. In an alternative approach, microfluidic channels can be directly ablated in bulk silica, polymer or chalcogenide glass to allow monolithic optofluidic integration.

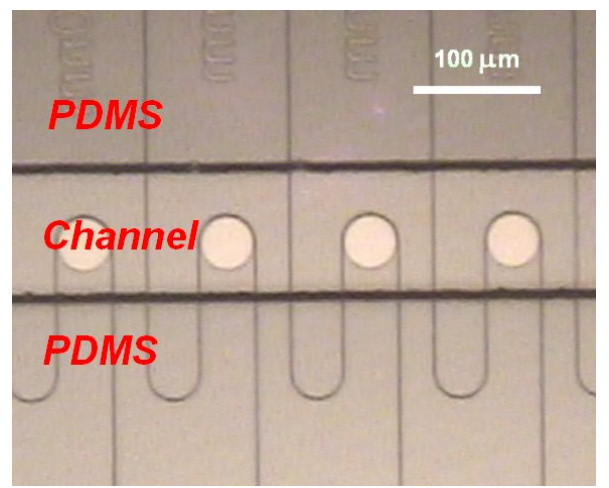

Fig. 1: Top view of $\mathrm{Ge}_{17} \mathrm{Sb}_{12} \mathrm{~S}_{71}$ optical resonators overlaid with bonded PDMS microfluidic channels.

During refractive index sensor testing, deionized (DI) water solutions of isopropanol (IPA) of varying concentrations were injected into the channels through a syringe pump, and the resonant peak shift due to ambient refractive index change was monitored in situ. The measurements with different concentrations of solutions were repeated twice to confirm reproducibility. TM polarization transmission spectra of a $\mathrm{Ge}_{17} \mathrm{Sb}_{12} \mathrm{~S}_{71}$ resonator in IPA solutions of various concentrations are shown in Fig. 2(a). The resonant wavelength shift as a function of IPA concentration and corresponding solution refractive index is plotted in Fig. 2(b), and a refractive index (RI) sensitivity of (182 \pm 5$) \mathrm{nm} / \mathrm{RIU}$ is inferred from the fitted curve slope. By applying a Lorentzian fit to the resonant peaks, we show that the resonant wavelength can be determined to an accuracy of $\sim 0.1 \mathrm{pm}$ limited by noise, corresponding to an index detection limit of $8 \times 10^{-7} \mathrm{RIU}$ and a time-normalized sensitivity $\mathrm{S}^{*}=2 \times 10^{6} \mathrm{~Hz}^{1 / 2} / \mathrm{RIU}$ [13]. Such a high sensitivity can be attributed to the narrow spectral width of optical resonance in a low-loss glass resonator. 


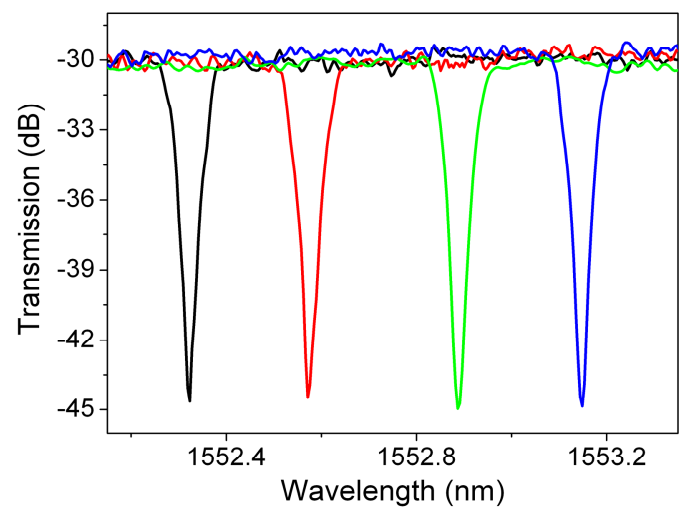

(a)

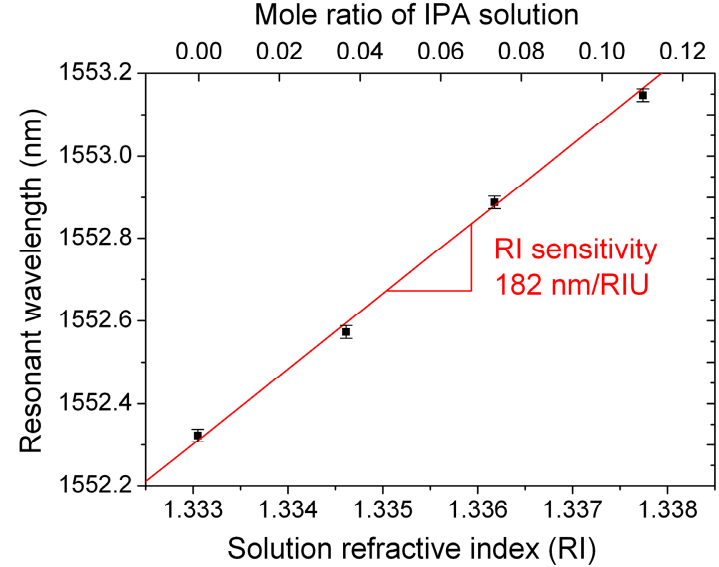

(b)

Fig. 2: (a) TM polarization transmission spectra of a $\mathrm{Ge}_{17} \mathrm{Sb}_{12} \mathrm{~S}_{71}$ microdisk in IPA solutions with four different concentrations; (b) Measured resonant peak wavelength shift as a function of IPA solution mole ratio concentration and corresponding solution refractive index.

\section{FEMTOSECOND LASER FACILITIES}

The laser source for femtosecond direct laser write processing (FLDW) was a home-built X-cavity $\mathrm{Ti}_{2} \mathrm{Al}_{2} \mathrm{O}_{3}$ oscillator. The length of the laser cavity was designed to be $\sim 5.75 \mathrm{~m}$ using a 1:1 telescope in one of the arms in order to achieve a maximum output pulse energy of $\sim 15 \mathrm{~nJ}$. The resulting repetition rate was $26 \mathrm{MHz}$. A schematic of the laser cavity is shown in Fig. 3. Laser light was focused with a 0.25NA microscope objective onto the sample, which was placed on a 3D translation stage (Newport VPX25).

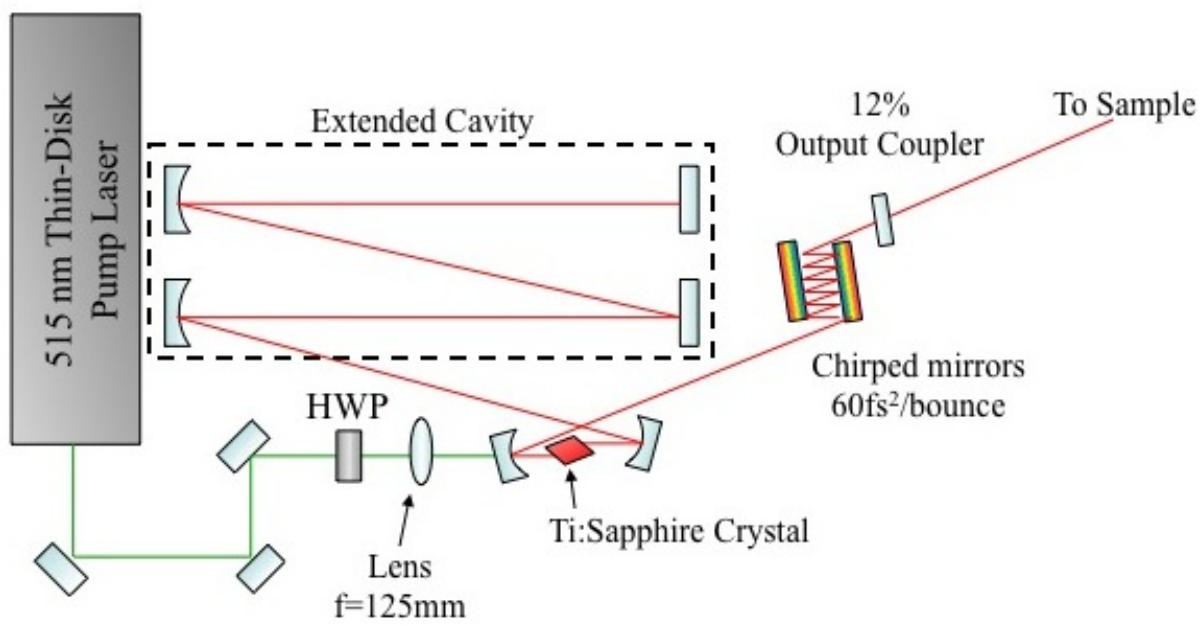

Fig. 3: Schematic of the extended cavity $\mathrm{Ti}: \mathrm{Al}_{2} \mathrm{O}_{3}$ laser 


\section{MATERIALS FOR FLDW}

A set of three chalcogenide glass film compositions were chosen for this study: $A_{36} \mathrm{Ge}_{6} \mathrm{~S}_{58}, \mathrm{As}_{42} \mathrm{~S}_{58}$, and $\mathrm{As}_{36} \mathrm{Sb}_{6} \mathrm{~S}_{58}$. These glasses were prepared as bulk samples and then deposited into thin films using thermal evaporation. Arsenicbased chalcogenide compositions were chosen for the femtosecond laser direct writing study as a previous study demonstrated a positive index change after femtosecond laser modification of $\mathrm{As}_{2} \mathrm{~S}_{3}$ [14], whereas the germanium-based composition displayed a negative refractive index modification [15].

\subsection{Glass preparation}

Bulk glasses in the systems and $\mathrm{As}-\mathrm{Ge}(\mathrm{Sb})-\mathrm{S}$ were prepared in $40 \mathrm{~g}$ batches. The glasses were melted from high purity elements As (Alfa: 99.999\%), Ge (Aldrich: 99.999\%), Sb (Alfa 99.9\%) and S (Cerac: 99.999\%). Starting materials were weighed and batched inside a nitrogen-purged glove box and sealed using a gas - oxygen torch under vacuum into quartz ampoules. Prior to sealing and melting, the ampoule and the $25 \mathrm{~g}$ batch were pre-heated to $100^{\circ} \mathrm{C}$, while under high vacuum, for $4 \mathrm{~h}$ to remove surface moisture from the quartz ampoule and the batch raw materials. The ampoule was then sealed with a gas-oxygen torch and heated to between 850 and $925^{\circ} \mathrm{C}$, depending on composition, and melted for 48 hours. A rocking furnace was used for melting in order to increase the homogeneity of the melt. Once fully homogenized, the melt-containing ampoule was air-quenched to room temperature. To avoid fracture of the tube and glass ingot, the ampoules were subsequently returned to the furnace for annealing for 15 hours at $40^{\circ} \mathrm{C}$ below the glass transition temperature $\left(\mathrm{T}_{\mathrm{g}}\right)$. Bulk glasses were cut, polished, and optically examined for homogeneity.

\subsection{Film deposition using thermal evaporation process}

Chalcogenide glass thin films with thicknesses of 400-1000 nm were prepared by thermal evaporation of the bulk glass used as targets on glass microscope slides. The evaporations were carried out in a 112 Evap-Sputter Station (PVD Sys. Inc) with a base pressure 2x10-7 Torr. A shutter system was used to control exposure time and a working distance of 8 $\mathrm{cm}$ was maintained between the target and substrate. During evaporation, the current and voltage on a molybdenum boat containing small pieces of bulk glass was monitored to bring the glass to a temperature just above the melting point in order to establish a vapor pressure in the chamber needed to maintain a constant deposition rate of approximately $2 \mathrm{~nm} / \mathrm{s}$. A thermostat stage was also employed to maintain the substrate temperature at $25^{\circ} \mathrm{C}$ throughout the deposition process. The resultant films were cleaved into 2 pieces. Films were stored in a darkened desiccator for approximately one week prior to annealing. One piece of each film was then annealed at $60{ }^{\circ} \mathrm{C}$ below the glass transition temperature of the corresponding bulk glass to allow relaxation to occur without inducing thermal stress or causing crystallization.

\section{WAVEGUIDE FABRICATION AND CHARACTERIZATION}

A series of waveguides were fabricated in each of the glass films using femtosecond laser direct writing with varying laser parameters. We have previously shown for several chalcogenide glass compositions that the magnitude of femtosecond laser induced photo-modifications are the largest for pulse energies just below the material ablation threshold [14-16]. Therefore, each of the films was irradiated at $90 \%$ of its ablation threshold $(0.12 \mathrm{~nJ})$ in order to compare the relative photosensitivity of each film and its capacity as a host material for waveguide fabrication. At this pulse energy, six waveguides with a varying number of laser pulses incident on the sample per laser focal spot were fabricated on each film. The photo-induced waveguides were then analyzed for modification of the surface profile and the refractive index in order to characterize the affect of laser irradiation on the physical and optical properties of the glass.

The surface profiles of the fabricated lines as a function of the number of pulses per spot normalized to the film thickness were measured using a Zygo NewView6300 3D Optical Profilometer and are given in Fig. 4. 


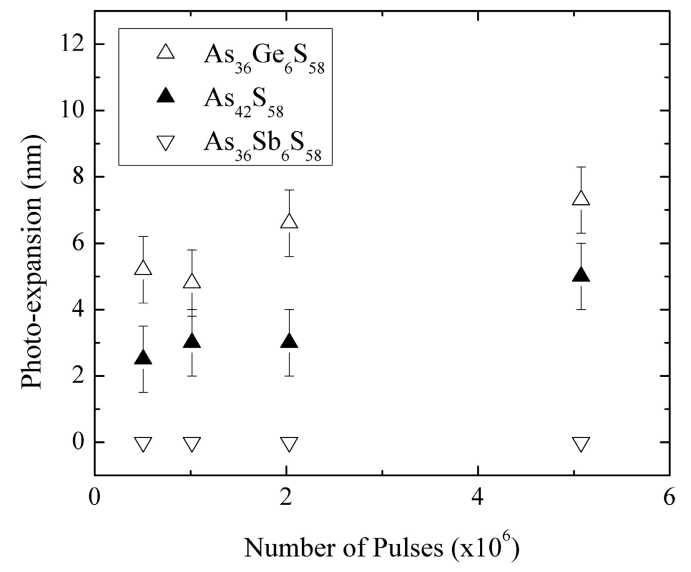

Fig. 4: Change in surface profile (photo-expansion) of laser-written lines in as-deposited $\mathrm{As}_{36} \mathrm{Ge}_{6} \mathrm{~S}_{58}, \mathrm{As}_{42} \mathrm{~S}_{58}$, and $\mathrm{As}_{36} \mathrm{Sb}_{6} \mathrm{~S}_{58}$ normalized to film thickness. Each film was irradiated at $90 \%$ of its ablation threshold.

Upon exposure to femtosecond laser irradiation, these films exhibit a photo-expansion or a decrease in density, which is consistent with previous observations of other chalcogenide compositions. The magnitude of this photo-expansion increases with the number of pulses per spot incident on the sample. This trend is consistent with previous studies of chalcogenide films and results from a higher number of bonds rearranged in the glass matrix with increasing energy dose absorbed by the glass [15]. Under these conditions, the $\mathrm{As}_{42} \mathrm{~S}_{58}$ and the $\mathrm{As}_{36} \mathrm{Ge}_{6} \mathrm{~S}_{58}$ film reacted similarly to the laser light. The surface of the $\mathrm{As}_{42} \mathrm{~S}_{58}$ film expanded up to $5 \mathrm{~nm}$, corresponding to an increase of the film thickness of $1.2 \%$, while the $\mathrm{As}_{36} \mathrm{Ge}_{6} \mathrm{~S}_{58}$ film thickness increased up to $7 \mathrm{~nm}$, corresponding to an increase of $0.8 \%$. It is interesting to point out that the $\mathrm{As}_{36} \mathrm{Sb}_{6} \mathrm{~S}_{58}$ film did not exhibit any observable photo-expansion. This result suggests that the addition of antimony atoms into the glass matrix affects the glass bond structure in such a way that the altered state induced by the laser irradiation has the same density as the initial structure. The height of the expansion varied slightly along the length of the fabricated feature, presumably due to a combination of slight material inhomogeneity, dust, and translation stage error. The error bars are an indication of this measured variance.

The refractive index of the fabricated structures was measured by placing the sample in one arm of an interferometer using the Zygo NewView 6300 and creating a white light interferogram as discussed in Refs [14-15]. In this configuration, any change in either the thickness or refractive index of the glass is manifested as a shift in the series of the linear fringes of the interferogram. A Fourier Frequency Analysis (FFA) was used to extract the femtosecond laserinduced modification of the optical path [18]. The induced refractive index change was then calculated using the independent surface profile measurement of the induced thickness change from Fig. 4 [15].

The refractive index measurements of the waveguides as a function of the number of pulses per spot are shown in Fig. 5. 


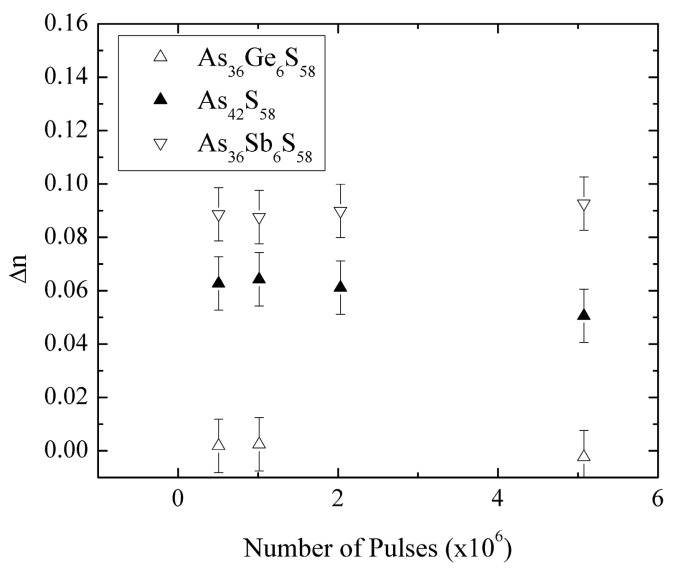

Fig. 5: Refractive index change for as-deposited samples of (a) $\mathrm{As}_{36} \mathrm{Ge}_{6} \mathrm{~S}_{58}$, (b) $\mathrm{As}_{42} \mathrm{~S}_{58}$, and (c) $\mathrm{As}_{36} \mathrm{Sb}_{6} \mathrm{~S}_{58}$

In these films, the variance in composition among the glass types has a significant impact on the magnitude of the refractive index change. It was found that $\mathrm{As}_{36} \mathrm{Ge}_{6} \mathrm{~S}_{58}$ had a small negative induced refractive index change $(\Delta \mathrm{n})$ of 0.005 , whereas $\mathrm{As}_{42} \mathrm{~S}_{58}$, and $\mathrm{As}_{36} \mathrm{Sb}_{6} \mathrm{~S}_{58}$ exhibited a large positive $\Delta \mathrm{n}$ of 0.06 and 0.09 respectively for $10 \mathrm{x} 10^{6}$ pulses per spot. However, the relationship between induced photo-expansion (density change) and refractive index change is not direct. This is illustrated by the observation that the $\mathrm{As}_{36} \mathrm{Sb}_{6} \mathrm{~S}_{58}$ composition had the largest $\Delta \mathrm{n}$ with no measured photoexpansion and that $\mathrm{As}_{42} \mathrm{~S}_{58}$ and $\mathrm{As}_{36} \mathrm{Ge}_{6} \mathrm{~S}_{58}$ had similar magnitudes of photo-expansion but vastly different induced $\Delta \mathrm{n}$. Because the refractive index is linked to both density and the material polarizability through the Lorentz-Lorenz equation [19], these observations indicate that fs laser irradiation modifies the polarizability and density in these materials by independent processes. The details and dynamics of this would be an interesting area of further research that has the potential to help explain and predict the photo-response of glasses to femtosecond laser irradiation.

\section{MICRO-CHANNEL FABRICATION}

In addition to the fabrication of waveguides, FLDW can also be used to fabricate micro-channels in glass. We present here the fabrication of a surface micro-channel in $\mathrm{As}_{42} \mathrm{~S}_{58}$ through femtosecond laser direct writing and subsequent wet chemical etching. Bulk material was used to allow for a greater etch depth and to characterize the compositiondependent kinetics of the etching process. A channel fabricated in this method is similar to the lithographically fabricated ones discussed in section 2 and can be used for fluid or gas transport in an integrated device once covered with a cap layer such as a PDMS mold or glass welded around the channel.

In the first fabrication step, a photo-modified line was written on the surface by focusing $0.17 \mathrm{~nJ}$ pulses onto the surface with a $0.25 \mathrm{NA}$ microscope objective and translating the sample such that $10 \times 10^{6}$ pulses per focal spot were incident on the sample $(10 \mu \mathrm{m} / \mathrm{s})$. As seen with the thin film irradiation, the irradiation resulted in a modification of the material bond structure leading to a decrease in density that can be exploited during the etching phase. Fig. 6 shows a cross section of the surface profile of the feature with a measured photo-expansion of $50 \mathrm{~nm}$ and a FWHM of $1.5 \mu \mathrm{m}$ taken with the Zygo NewView 6300. 


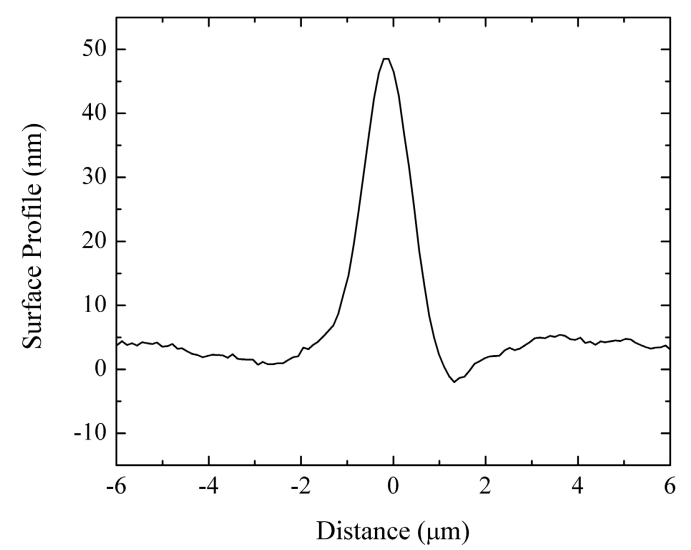

Fig. 6: Surface profile (height) of photo-modified line in bulk $\mathrm{As}_{42} \mathrm{~S}_{58}$ fabricated by exposure to $0.17 \mathrm{~nJ}$ femtosecond laser pulses at $10 \times 10^{6}$ pulses per focal spot showing the first step of the micro-channel fabrication process.

The photo-modified line was then converted from a relief line to an etched micro-channel by immersing the sample in a solution of $62.5 \%$ Propylamine for $80 \mathrm{~s}$. The sample was suspended in the solution above a magnetic stirring capsule in order to facilitate debris removal. The Propylamine solution preferentially etched the photo-modified glass, resulting in a channel. It should be noted that as the laser irradiation step created a raised surface profile, the height of the expansion was only a fraction of the total post-etch channel depth and did not significantly limit from the resultant channel depth. Fig. 7 shows a cross section of the final trench resulting from etching the relief line shown in Fig. 6 taken with the Zygo NewView 6300 , measuring $5.38 \mu \mathrm{m}$ wide and $2.3 \mu \mathrm{m}$ deep. The increased width of the channel is likely due to an increased exposure of the sidewalls to the etchant relative to the base of the trench and would then be controlled by the total etching time. Small channels of this size are ideal for applications involving low sample volumes and can be used for fluid or gas transport.

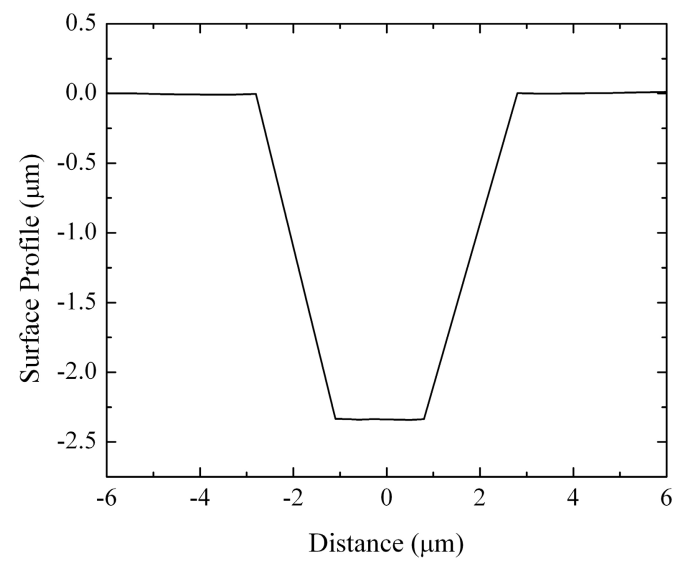

Fig. 7: Surface profile of a micro-channel fabricated in $\mathrm{As}_{42} \mathrm{~S}_{58}$ by femtosecond laser irradiation and subsequent wet etching in a 62.5 vol\% Propylamine solution.

\section{CONCLUSION}


We have demonstrated the fabrication of optical and fluidic structures in three compositions of chalcogenide glasses using two fabrication methods. It has been shown that while similar in chemistry, the glass systems examined vary in their structural attributes and laser response. With a CMOS-compatible lift-off technique, a high-Q optical resonator coupled to a PDMS microchannel for the detection of isopropanol (IPA) has been demonstrated. Femtosecond laser direct writing [FLDW] has been used to fabricate both optical waveguides and micro-channels in chalcogenide glass towards the development of integrated optofluidic circuits. The magnitudes of the photo-induced refractive index change and photo-expansion were shown to be independent of each other and differed significantly with the composition of the glass, which indicates a complex physical response to the absorbed laser energy. Micro-channel structures were fabricated using a two-step process involving photo-modification of the material in the desired pattern and subsequent sample wet etching, resulting in a $5.38 \mu \mathrm{m}$ wide and $2.3 \mu \mathrm{m}$ deep micro-channel. The fabrication of integrated optical and fluidic structures on a single chalcogenide glass chip will extend the functionality of lab-on-a-chip devices to compounds with optical signatures that extend into the mid-IR spectrum.

\section{ACKNOWLEDGEMENTS}

Funding for this work was provided by DOE (Contract \# DE-FG52-06NA27502), NSF (Contract \# ECS 0437614 and ENG 0649230), and the State of Florida.

\section{DISCLAIMER}

This paper was prepared as an account of work supported by an agency of the United States Government. Neither the United States Government nor any agency thereof, nor any of their employees, makes any warranty, express or implied, or assumes any legal liability or responsibility for the accuracy, completeness or usefulness of any information, apparatus, product or process disclosed, or represents that its use would not infringe privately owned rights. Reference herein to any specific commercial product, process, or service by trade name, trademark, manufacturer, or otherwise does not necessarily constitute or imply its endorsement, recommendation, or favoring by the United States Government or any agency thereof. The views and opinions of authors expressed herein do not necessarily state or reflect those of the United States Government or any agency thereof.

\section{REFERENCES}

[1] Psaltis, D., Quake, S. and Yang, C. "Developing optofluidic technology through the fusion of microfluidics and optics." Nature 442(27), 381-386 (2006).

[2] Marcinkevicius, A., Juodkazis, S., Watanabe, M., Miwa, M., Matsuo, S., Misawa, H, and Nishii, J. "Femtosecond laser-assisted three-dimensional microfabrication in silica." Opt. Lett. 26(5), 277-279 (2001).

[3] Kovac, J.R. and Voldman, J. "Intuitive, Image-Based Cell Sorting Using Optofluidic Cell Sorting." Anal. Chem. 79, 9321-9330 (2007).

[4] Osellame, R., Maselli, V. and Martinez Vazquez, R. "Integration of optical waveguides and microfluidic channels both fabricated by femtosecond laser irradiation. " Appl. Phys. Lett. 90, 231118 (2007).

[5] Compton, D.A.C., Hill, S.L., Wright, N.A., Druy, M.A., Piche, J., Stevenson, W.A. and Vidrine, D.W. "In Situ FT-IR Analysis of a Composite Curing Reaction Using a Mid-Infrared Transmitting Optical Fiber", Appl. Spectrosc. 42, 972979 (1998). 
[6] Sanghera, J.S., Kung, F.H., Pureza, V.Q., Miklos, R.E. and Aggarwal, I.D. "Infrared Evanescent-Absorption Spectroscopy with Chalcogenide Glass-Fibers", Appl. Optics 33(27), 6315-6322 (1994).

[7] Homola, J., Yee, S.S. and Gauglitz, G. "Surface plasmon resonance sensors: review," Sens. Actuators B 54, 3-15 (1999).

[8] Levi, O., Lee, M.M., Zhang, J., Lousse, V., Brueck, S.R.J., Fan, S. and Harris, J.S. "Optical Characterization and Sensitivity Evaluation of Guided-Resonances in Photonic Crystal Slabs for Biosensing Applications," Conference on Lasers and Electro-Optics 2007 (2007).

[9] Liang, W., Huang, Y., Yong, X., Lee, R.K. and Yariv, A. "Highly sensitive fiber Bragg grating refractive index sensors," Appl. Phys. Lett. 86, 151122 (2005).

[10] Petit, L., Carlie, N., Adamietz, F., Couzi, M., Rodriguez, V. And Richardson, K.C. "Correlation between physical, optical and structural properties of sulfide glasses in the system Ge-Sb-S," Mater. Chem. Phys. 97(1), 64-70 (2006).

[11] Hu, J., Tarasov, V., Carlie, N., Petit, L., Agarwal, A., Richardson, K. and Kimerling, L. "Fabrication and Testing of Planar Chalcogenide Waveguide Integrated Microfluidic Sensor," Opt. Express 15(5), 2307-2314 (2007).

[12] Hu, J., Tarasov, V., Carlie, N., Feng, N., Petit, L., Agarwal, A., Richardson, K. and Kimerling, L. "Si-CMOScompatible lift-off fabrication of low-loss planar chalcogenide waveguides," Opt. Express 15(19), 11798 (2007).

[13] Hu, J., Sun, X., Agarwal, A. and Kimerling, L. "Design guidelines for optical resonator biochemical sensors," submitted to J. Opt. Soc. Am. B.

[14] Zoubir, A., Richardson, M., Rivero, C., Schulte, A., Lopez, C., Richardson, K., Ho, N. and Vallee, R. "Direct femtosecond laser writing of waveguides in As2S3 thin films." Opt. Lett. 29(7), 748-750 (2004).

[15] Anderson, T., Petit, L., Carlie, N., Choi, J., Hu, J., Agarwal, A., Kimerling, L., Richardson, K. and Richardson, M. "Femtosecond laser photo-response of Ge23Sb7S70 films." Opt. Express 16(24), 20081-20098 (2008).

[16] Petit, L., Carlie, N., Anderson, T., Couzi, M., Choi, J., Richardson, M. and Richardson, K. "Effect of IR femtosecond laser irradiation on the structure of new sulfo-selenide glasses." Opt. Mat. 29, 1075-1083 (2007).

[17] Petit, L., Carlie, N., Anderson, T., Choi, J., Richardson, M. and Richardson, K. "Progress on the Photoresponse of Chalcogenide Glasses and Films to Near-Infrared Femtosecond Laser Irradiation: A Review," IEEE J. of Special Topics in Quantum Electronics 14(5), 1323-1334 (2008).

[18] Krishnaswami, K., Bernacki, B.E. and Ho, N. "Lateral shearing interferometer for measuring photoinduced refractive index change in As2S3" Rev. Sci. Instrum. 79, 095101 (2008).

[19] Born, M. and Wolf, E. [Principles of Optics], Seventh (Expanded) ed., Cambridge University Press (1999). 